Association for Information Systems AIS Electronic Library (AISeL)

Wirtschaftsinformatik Proceedings 2005

Wirtschaftsinformatik

February 2005

\title{
Key Factors for a Better Understanding of Mobile Java Games Customers
}

Mitra Arami

Vienna University of Economics and Business Administration

David Meyer

Vienna University of Economics and Business Administration

Antje Sester

Vienna University of Economics and Business Administration

Follow this and additional works at: http://aisel.aisnet.org/wi2005

\section{Recommended Citation}

Arami, Mitra; Meyer, David; and Sester, Antje, "Key Factors for a Better Understanding of Mobile Java Games Customers" (2005). Wirtschaftsinformatik Proceedings 2005. 19.

http://aisel.aisnet.org/wi2005/19

This material is brought to you by the Wirtschaftsinformatik at AIS Electronic Library (AISeL). It has been accepted for inclusion in Wirtschaftsinformatik Proceedings 2005 by an authorized administrator of AIS Electronic Library (AISeL). For more information, please contact elibrary@aisnet.org. 
In: Ferstl, Otto K, u.a. (Hg) 2005. Wirtschaftsinformatik 2005: eEconomy, eGovernment, eSociety; 7. Internationale Tagung Wirtschaftsinformatik 2005. Heidelberg: Physica-Verlag

ISBN: 3-7908-1574-8

(C) Physica-Verlag Heidelberg 2005 


\title{
Key Factors for a Better Understanding of Mobile Java Games Customers ${ }^{1}$
}

\author{
Mitra Arami, David Meyer, Antje Sester \\ Vienna University of Economics and Business Administration
}

\begin{abstract}
This paper presents first results of a research project conducted at the Vienna University of Economics and Business Administration. The focus of the project is to analyze customer perceptions towards Mobile Java Games and to identify gaps in Mobile Java Games research. A major finding is that transaction data typically collected by Mobile Service Providers can deliver only limited explanations on customer behavior. Thus, the existing information should be enriched by additional data such as consumer surveys and market research. This would enable firms to improve their market strategies.
\end{abstract}

Keywords: M-Commerce,Mobile Java Games, Mobile Entertainment, Marketing

\section{Introduction}

Content-based mobile services are already making an important contribution to the revenue of mobile service providers, and mobile games will be the biggest contributor to the growth of mobile content within the next years [Ande02]. Because of these future prospects for mobile content and entertainment services, it is likely that a large number of companies will be attracted to this market.

Without doubt mobile games based on Java 2 Micro Edition (Mobile Java Games) represent an important sub-segment as they offer a unique span of performance characteristics [Gele04, Datc02, Datm01]. Mobile Java Games (MJG) have been introduced to the European market in 2002 [Abou04].

The main research goal of the project presented in this paper is to analyze critical factors that have a positive effect on users' attitudes towards usage of MJG. The use of these factors lies in providing a fundament on which focused marketing strategies can be developed. This includes the question for customer preferences and the existence of specific customer segments with their own special prefer-

\footnotetext{
We would like to thank Benjamin Spiss and Roland Zechmeister for their collaboraton in this project. Also, we are particularly grateful to the referees for their useful suggestions and comments.
} 
ences. Finding out about customers' preferences should ideally lead to a deeper understanding of what kind of picture of the product customers have in their mind, comprising, e.g., the game's complexity and the type of content. Important questions to understand how revenue streams of providers will develop are the intensity of use and potential limitations from the customer side (technological barriers, pricing of service, etc.).

This project is scheduled in four phases: 1) Literature study, 2) Explorative Analysis of customer data, 3) Qualitative analysis, and 4) Quantitative online survey.

The first phase is surveying: after analyzing the information gathered, we identify areas of controversy and formulate hypotheses for further research steps. The second phase is an explorative analysis of customer data, provided by an Austrian mobile service provider, which includes a cluster analysis. Again, hypotheses for the further research are derived from the findings. In the third phase, we apply a qualitative analysis to get deeper information about different aspects of mobile Java gaming. On the one hand, user focus groups with different sociodemographic characteristics will be asked to download and play Java Games, and be questioned about their experiences. Second, experts from the supply side of Java Games will be interviewed about their market view. Finally, both positions will be compared, and synthesized in a quality workshop. The results of phases 13 will be the basis of a customer survey conducted in the fourth phase. The results of this survey will be used to formally test our hypotheses within the framework of a standard customer acceptance model.

The paper at hand reports the results of phases 1 and 2 (Literature Review and Explorative Data Analysis), and concludes on the next project phases.

\section{Literature Review}

Mobile Gaming provides entertaining services via wireless technology to mobile devices. Even though Mobile Games are a recent phenomenon there is a variety available in most developed markets [Voda04]. Different existing Mobile Games Business Models such as SMS Games, Browser Games, Native Operating System Games, and MJG can be distinguished [Noki03]. The focus of this paper is on MJG.

Sun Microsystems' Java 2 Micro Edition (J2ME) technology has become the de facto standard in the interpreted mobile gaming field. J2ME based games have changed the users' gaming experience not only by providing enhanced graphical features. Due to the fact that java applications reside on the handsets themselves instead of the network they are more robust, quicker to load than WAP applications and at the same time able to store user preferences [Gele04]. After the users have downloaded a game they can play anytime they wish either on-line in a mul- 
tiplayer mode or off-line in a single-player mode [e.g. Mobi04]. Games can be ordered either over the Internet or the mobile device.

By the beginning of 2003, tens of operators and a high number of service providers/aggregators all over the world had already successfully trialed or launched MJG [Noki04]. The early results from many of these wireless Java service launches have been very encouraging. Many operators in Asia, Europe and the US have reported rapid user adoption and significant traffic increases from Java services. Here some corporate reports about early Java launches:

- 25 carriers in 34 markets have deployed or trialed wireless Java Games and the number is growing rapidly [Source: Sun Microsystems, February 2003]

- US operator Nextel reported 660.000 Java downloads in 2002 [MMAN]

- German Mobile Portal Provider Jamba! Reports 140.000 Java downloads / month in November 2002 [Jamb03]

Note, however, that these statements have to be taken with care as they might be biased.

According to [Noki04] the key success factors of MJG are:

- User acceptance:

- Attractive content and ease of use

- 1st download is the crucial moment of truth (most providers offer MJG as try and buy products so the first download is the most important part of the sales process since consumers typically adopt their attitude after the first try)

- Best content at launch

- Active educational point of sales (POS) marketing (since MJG are not selfexplanatory, demonstration of the functionality becomes part of the sales process)

- Ensure out of box readiness/service activation (no need for complicated installation and initial configuration)

- Easy service discovery by WAP, SMS, Web (functioning of MJG should not depend on specific communication protocols)

- Business model

- Work with content partners and create win/win business models

- Need for industry wide quality assurance processes

Corresponding to the key learnings on MJG and their success factors from a marketing perspective, essential considerations for the success MJG will be demonstrated in this section. A brief overview on existing literature and academic re- 
search regarding MJG characteristics, game classifications, pricing and payment, branding, and the customer groups will be given. Due to the apparent lack of documented research on MJG, we occasionally had to resort to more general literature.

\subsection{Characteristics of Mobile Java Games}

Mobile Commerce applications show distinctive characteristics, which represent a qualitative differentiation from fixed-line applications. As Mobile Gaming in general and MJG in specific can be seen as a sub-group of Mobile Commerce Applications it is likely that these characteristics can be applied to MJG as well. These characteristics can be summarized as follows:

- Ubiquity: The ubiquity of the services permits the enjoyment of them wherever the user feels the need, for example, while waiting in the train-station. [Müll99]

- Accessibility: The services are available at any time and immediately. It has been observed that many users access wireless services in niche time and have different usage patterns than people who go online through PCs [Mizu $\left.{ }^{+} 01\right]$.

- Reachability: From a push-perspective, mobile services allow connection with a user, with his permission, anywhere and anytime. This allows immediate interaction in communication applications and enhances the possibilities to contact possible partners for multiplayer games. The entertainment services can be customized to the user's location. This allows better-targeted entertaining services [Müll99].

- Personalization: Wireless devices are regarded as very personal items. Personalized services create strong customer relationships, thus encouraging transactions while preventing users from switching to different services [GrHu00].

On the other hand there are some limitations of Mobile Commerce compared with wired Internet services. The most emphasized aspects are limited user interface capabilities and connection speed [WAP99]. A recent Giga Information Group report pointed out that phones that use Java might not be ready for the market. "Java is still very immature on small devices," the report says. Recent recalls "are more proof that Java phones are not ready for prime time with the mass-market consumer or the enterprise" [Giga00]. In addition, due to technological restrictions, MJG currently are limited to off-line and single user-gaming [Wire04]. According to the literature review, we formulate following hypothesis:

H1: a) Currently, the availability of Java Games enabled mobile devices is insufficient. b) The cost of acquiring these devices is still too high.

H2: Developing applications for intelligent, automatic personalization on mobile devices, is a success factor for $M J G$. 


\subsection{Classification of MJG}

In general there is no defined pattern for the classification of MJG.

In their studies, Frost and Sullivan describe the following play categories: Action/Combat, Adventure, Casino/Gambling, Sport, Parlor/Arcade (society plays), Puzzle, and Trivia (Quiz plays) [FrSu02, p. 2-7]. John Romero, the inventor of PC games such as Doom and founder of Monkeystone Games, believes in the opportunity for puzzle games such as Tetris [Rome03]. Jussi Pekka Partanen's opinion is that the most popular games will be simple games such as Bingo, card-games and quizzes [Part01]. Games from these categories require more training and-due to their complexity-are not suitable for mobile devices. He calls this principle "5 minute fun", mobile games must be simple and fast downloadable. According to the literature review, we formulate following hypotheses:

H3: Simpler games are more successful than complex ones.

\subsection{Pricing and Payment}

Clear and simple pricing models are essential to achieve user acceptance. Pay per download and bill to phone ${ }^{2}$ is maybe the easiest for the user to gasp. Also simple monthly subscription based charging models have been used successfully and in innovative way. Too high prices will kill market growth whereas too low prices mean leaving value on the table. Several of the successful Java launches by operators so far have applied low pricing to stimulate service mass-market uptake. A fixed monthly fee could be an easy solution, but is not very attractive to customers. The market is young and developing and customers want to be able to change service providers rapidly. In this model the content providers could also be paid a fixed amount for a game that the service provider is offering. Download-based charging model will most likely be the mostly used revenue model. Content providers are paid a certain provision of each transaction. This way the content provider's income is directly related to the success of the game among the end users, which would give the content providers the pressure of making higher quality games all the time. Service providers themselves would have to take the risk of developing games. [Part01]

The feasible billing methods should be developed in very early stage of offering services. The situation will be the same as for early Internet business models: if many free services are available before the service providers start charging for

Bill to phone is a payment method. Normally there are different payment options such as Credit Card or Bill to Phone. 
their services, people will not start paying for them since they got used getting them for free.

At the time being, most of mobile service providers offer a uniform pricing model for MJG (see Table 1). However, it remains mostly unclear to customers whether these prices include Airtime charge. These hidden costs might be a factor preventing customers from purchasing MJG.

\begin{tabular}{|l|l|l|l|l|}
\hline Attribute & T-Mobile $^{\mathbf{3}}$ & One $^{\mathbf{4}}$ & $\mathbf{A 1}^{\mathbf{5}}$ & Telering $^{\mathbf{6}}$ \\
\hline Black \& White & $1,50-3,50 €$ & - & $2,99 €$ & - \\
\hline Color & $2,50-3,50 €$ & $3-5 €$ & $4,99 €$ & $3,90 €$ \\
\hline Non-Branded & $2,50-4,50 €$ & $3-5 €$ & $4,99 €$ & $3,90 €$ \\
\hline Branded & $3,50-4,50 €$ & $3-5 €$ & $4,99 €$ & $3,90 €$ \\
\hline
\end{tabular}

Table 1: Austrian Mobile Provider Pricing Model for MJG [own work, T-Zones, One Game, A1Games, Telering Handyfun, July 2004].

According to the literature review, we formulate following hypothesis:

H4:"Pay by Download" without Airtime charge is the most accepted charging mode for MJG.

\subsection{Branding}

As branded MJG we consider games based on existing brands such as popular console or computer games, latest events such as movies, TV-shows and sportsevents, and even people like pop-idols or soccer teams [Kell03]. Developers realize that branded games have a high user penetration [FrSu02, 2-28]. The actual brands, which are preferred by users, are likely to differ among different cultures [Kang04]. The functions brands take over from the consumers' perspective remain mostly uninvestigated. Hence, it is hard to say what importance brands have vis-àvis other factors such as social elements of games or games' prices.

Coming from "classical branding", Keller identifies seven possible roles a brand can play from a consumer's perspective [Kell03]:

- Identification of source of product

\footnotetext{
cf. http://www.t-zones.at/at/09t_games/

cf. http://www.one.at

cf. http://games.aon.at

cf. http://www.telering.at/Content.Node/fun/3446.php
} 
- Assignment of responsibility to product maker

- Risk reducer

- Search cost reducer

- Promise, bond, or pact with maker of product

- Symbolic device

- Signal of quality

As consumers have only limited possibilities to test games in advance it is likely that the brand can be seen as a risk reducer and a promise. Furthermore, the name of the actual maker of the game itself is in many cases not displayed. ${ }^{7}$ The brand of the game can therefore not be regarded as an assignment of responsibility to the product maker or the identification of source of product unless customers transfer these roles to the provider of the games. Another function of branding that is possibly delegated to the provider is risk reduction.

Although these assumptions remain only very vague and clearly further investigations are required, it can be seen that branding can play a role on two levels: The first level is the product itself as defined above. The second level can be providers themselves which can benefit from their corporate brand. Conversely, providers can obtain a positive effect on their corporate brand by selling new innovative products such as Java Games [Kell03].

H5: a) Branded Java Games are preferred to non-branded Java Games. b) This effect is amplified for corporate brands that stand for a high technological competence.

H6: Selling Java Games has a positive effect on the corporate brand of the service provider.

\subsection{Consumer Groups}

As with many new services or products, market awareness is low at the beginning. The key barrier to overcome is to get the users to do the first critical download. Mobile Service Provider that have achieved rapid uptake of new services have invested significantly in easy to understand marketing, educating the mobile users on what benefits Java services can offer and how they can discover and download Java applications.

Regarding to Literature, following three users groups of mobile games can be distinguished:

7 During our website analysis of game prices we have also noticed that in most cases the productmaker of MJG is not displayed. 
- Kids and Teenagers: They are growing up in the wireless environment and in the world of the Internet. Although their parents are the actual subscribers to the mobile services, many kids are already regular users of mobile devices. Kids and teenagers are also heavy users of game consoles. It is likely that these users will be among the first to link their consoles to wireless phones to play games against their friends [Brio01]. The socializing aspect has a particularly important value to kids, as they have a lot of free time [Hall01]. Thus they will undeniably be among the most dedicated users of mobile entertainment.

- Young adults: Across the world, there are currently numerous young adults with large budgets. They generally share a strong demand for brand products, and are likely to turn to wireless phones for daily entertainment services. The span of the group is fairly wide, beginning with European high school and university students with minimal expenses, as they are still supported by their parents. The other end of the span consists of users in their mid-to-late $20 \mathrm{~s}$, who often already have salary incomes and are often single. If already married, dual incomes are common in this age group. They therefore have plenty of money to spend on their life-style. They are tech savvy and perceptive to new trends. [Inst01].

- Business Users: European business users will not be as strong as the aforementioned users. Using the devices primarily for infotainment and communication, popular content will include news \& weather [Noki 00].

A more detailed categorization is provided by [Ande02], which advises that understanding peculiarities of user demographics is important (see ). A consistent feature among the segments described by Andersen Research is the young age of mobile game players. Another finding is that most mobile gamers have console gaming background. According to the literature review, we formulate following hypotheses:

H7: The market for mobile java games is likely segmented as the market for mobile games.

H8: The usage of MJG will be moderated by gender and age, such that the effect will be stronger for men and particularly for younger men. 


\begin{tabular}{|l|l|l|l|}
\hline & $\begin{array}{l}\text { Mobile } \\
\text { casual gamers }\end{array}$ & $\begin{array}{l}\text { From mobile casual } \\
\text { gaming }\end{array}$ & $\begin{array}{l}\text { From traditional } \\
\text { hard-core gaming }\end{array}$ \\
\hline Demography & $\begin{array}{l}\text { Young, both sexes } \\
\text { and all ages }\end{array}$ & Young, both sexes & Young, males \\
\hline $\begin{array}{l}\text { Console gaming } \\
\text { background }\end{array}$ & Some & Most & All \\
\hline $\begin{array}{l}\text { Reasons for mobile } \\
\text { gaming }\end{array}$ & Time-killing & Hobby & Hobby \\
\hline Type of game & Simple & Simple \& Complex & Complex \\
\hline $\begin{array}{l}\text { Success factor } \\
\text { Game play }\end{array}$ & $\begin{array}{l}\text { Game play and } \\
\text { Graphics }\end{array}$ & Minority \\
\hline $\begin{array}{l}\text { Mobile gaming user } \\
\text { population }\end{array}$ & Majority & Minority & Minority \\
\hline Uptake & Now & Casual & $\begin{array}{l}\text { An introduction in } \\
\text { relevant handsets }\end{array}$ \\
\hline
\end{tabular}

Table 2: Mobile Gaming Customer Segmentation [Ande02]

\section{Data Analysis}

In this section, we summarize the results of our analysis of the mobile providers' transactional data. We first introduce the methodology employed, followed by a description of the data set. Then, we have a closer look at some explanatory variables potentially influencing the number of downloads, and present the results of a cluster analysis. The section concludes with a discussion of the results and on implications for the next two phases of the project.

\subsection{Methodology}

Analyzing the transaction data of Java Games collected by mobile service providers appeals as the logical starting point for marketing measures. This data has two advantages: First, as most data collections of this kind, they combine (at least some) socio-demographic data of customers with transactional data. As such, they are predestined to be used as a basis for clustering [Ults02]. Second, they are collected automatically by the download and billing processes, and can be accessed 
by the service providers "ad hoc", in contrast to external survey data which necessitates additional investments of time and money.

In our analysis, we first employ explorative data analysis to extract the main characteristics of the data set. We try to find influencing factors of the number of downloads mostly by exploring conditional bar charts to see how the distribution of the number of downloads varies in subpopulations of interest (e.g. male/female users, etc.). Second, we try to find a segmentation of the customers with respect to explanatory variables, hoping to find groups with a profiled download behavior (e.g., clusters of heavy users, or clusters with very low downloads). As segmentation technique, we use Self-Organizing Maps (SOM) introduced by [Koho95], a data mining method for simultaneous dimension reduction, clustering, and visualization of high-dimensional data sets [Kask95, KaKo97]. SOMs have successfully been employed in the field of marketing (e.g. [Curry $\left.{ }^{+} 03\right]$ and [Ults02] for an application in the mobile phone market).

\subsection{Description of the Data Set}

The data provided by the Austrian mobile phone provider was taken from the company's data warehouse and basically consists of transaction data of game downloads from February, 2003, to February, 2004 (74.703 entries in total), generated by 19.838 customers (Post-paid users only). Besides information on the game (title, genre) and the customers' contract (rate, average turnover), the data includes socio-demographic variables such as age, gender, location, and professional background. The rates have been grouped into categories. The summary statistics of these variables are shown in Table 3: we indicate the level proportions for categorical variables and a 5-number-summary for the continuous one (turnover).

A few remarks are appropriate. First, the high proportion of male customers $(68,17 \%)$ seems surprising. Second, the proportion of customers from Lower Austria $(28,8 \%)$ is much higher than might be expected from the official population figures (19,3\% - see [Stat04]). Conversely, the proportions are lower for Vorarlberg (data set: $1,81 \%$ / population figure: $6,7 \%$ ) and Salzburg (data set: $2,87 \%$ / population figure: $6,4 \%$ ), so we clearly have regional effects. Third, customers basically focus on two groups of rate categories: the economy rates mean lower ground fees and higher connection fees, the heavy usage rates higher ground fees and lower connection fees. Finally, the genres compare well to the game categories found in the literature, but are grouped differently: e.g., "Parlor/Arcade" and "Casino/Gambling" correspond to "Chance \& Strategy" in our data set, whereas we find "Jump'n'run" as a category on its own. Clearly, "Shoot'em'up" games correspond to the "Action/Combat" category. Interestingly, no puzzle and quiz games are offered by this Mobile Service Provider. 


\begin{tabular}{|c|c|c|}
\hline Genre & $\begin{array}{r}\text { Adventure } \\
\text { Chance \& Strategy } \\
\text { Jump'n'run } \\
\text { Shoot'em'up } \\
\text { Sport \& Racing } \\
\text { Not Assigned }\end{array}$ & $\begin{array}{r}8,07 \% \\
16,23 \% \\
15,74 \% \\
15,28 \% \\
23,89 \% \\
20,79 \% \\
\end{array}$ \\
\hline $\begin{array}{l}\text { Average } \\
\text { Turnover (EUR) }\end{array}$ & $\begin{array}{r}\text { Min } \\
1 \mathrm{Q} \\
\text { Median } \\
3 \mathrm{Q} \\
\text { Max }\end{array}$ & $\begin{array}{r}0,00 \\
22,12 \\
37,97 \\
62,79 \\
2.298,00\end{array}$ \\
\hline Age & $\begin{array}{r}0-18 \\
19-24 \\
25-34 \\
35-44 \\
45-55 \\
56+ \\
\end{array}$ & $\begin{array}{r}7,01 \% \\
30,12 \% \\
22,46 \% \\
24,47 \% \\
13,06 \% \\
2,88 \% \\
\end{array}$ \\
\hline Gender & $\begin{array}{r}\text { Male } \\
\text { Female }\end{array}$ & $\begin{array}{l}68,17 \% \\
31,83 \%\end{array}$ \\
\hline Family Status & $\begin{array}{r}\text { Married } \\
\text { Non-married }\end{array}$ & $\begin{array}{l}34,06 \% \\
65,94 \%\end{array}$ \\
\hline Location & $\begin{array}{r}\text { Vienna } \\
\text { Lower Austria } \\
\text { Upper Austria } \\
\text { Styria } \\
\text { Carinthia } \\
\text { Tyrolia } \\
\text { Burgenland } \\
\text { Salzburg } \\
\text { Vorarlberg }\end{array}$ & $\begin{array}{r}17,00 \% \\
28,05 \% \\
16,56 \% \\
13,30 \% \\
8,96 \% \\
8,13 \% \\
3,32 \% \\
2,87 \% \\
1,81 \%\end{array}$ \\
\hline $\begin{array}{l}\text { Professional } \\
\text { Background }\end{array}$ & $\begin{array}{r}\text { Services } \\
\text { Metalworking Industry } \\
\text { Retailing } \\
\text { Building Industry } \\
\text { Manufacturing } \\
\text { Tourism } \\
\text { [Others, not listed] }\end{array}$ & $\begin{array}{r}16,24 \% \\
13,21 \% \\
12,96 \% \\
10,29 \% \\
8,15 \% \\
7,44 \% \\
31,71 \% \\
\end{array}$ \\
\hline Rate & $\begin{array}{r}\text { Economy } \\
\text { Heavy-Usage } \\
\text { Other }\end{array}$ & $\begin{array}{r}62,65 \% \\
35,18 \% \\
2,17 \% \\
\end{array}$ \\
\hline
\end{tabular}

Table 3: Summary Statistics of Transaction Data 


\subsection{Download Analysis}

The count distribution of customers downloading games repeatedly is shown in Figure 1 (74.708 downloads, 19.838 transactions):

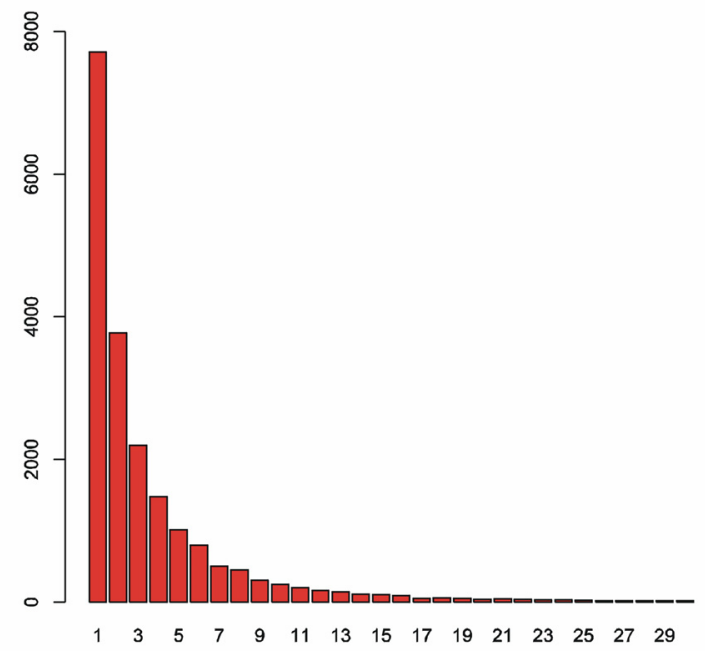

Figure 1: Counts of Repeated Downloads 2003

This Figure illustrates the fact that a major part of the customers $(7.708 / 40,1 \%)$ downloaded only once, only half as much (3.773 / 19,2\%) twice, 2.196 customers $(11,3 \%)$ made three downloads and so on, yielding an exponential-like, fastdecreasing distribution. Obviously, the rate of recurrent users is very low, and this first finding calls for more investigation. Exploring the download distribution in different sub-populations for different combinations of age, gender, and location combinations yields the same fast-decreasing structure. Conversely, the customer groups defined by the different number of downloads exhibit the same sociodemographic profile.

A major concern is posed by the data quality. Consider Figure 2 depicting the number of downloads by age breaks: 


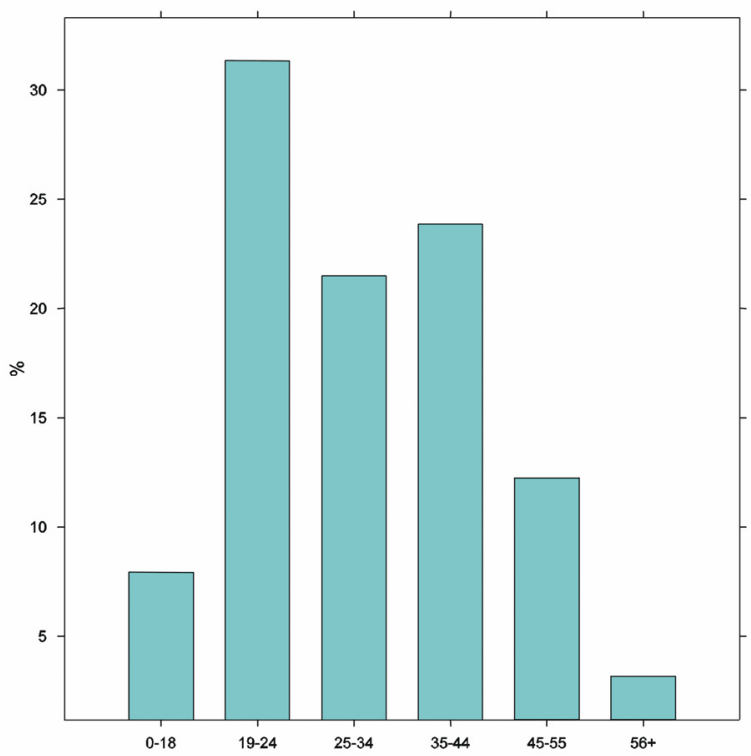

Figure 2: Downloads 2003, grouped by Age, $(\mathrm{N}=74.703)$

Given the fact that most Austrian children own a mobile phone [Mobi03], the low rate for under-aged customers cannot reflect the real usage figures. When we add a further split by gender (see Figure 3), we similarly find that most female customers seem to be middle-aged, in contrast to their mostly younger male counterparts:

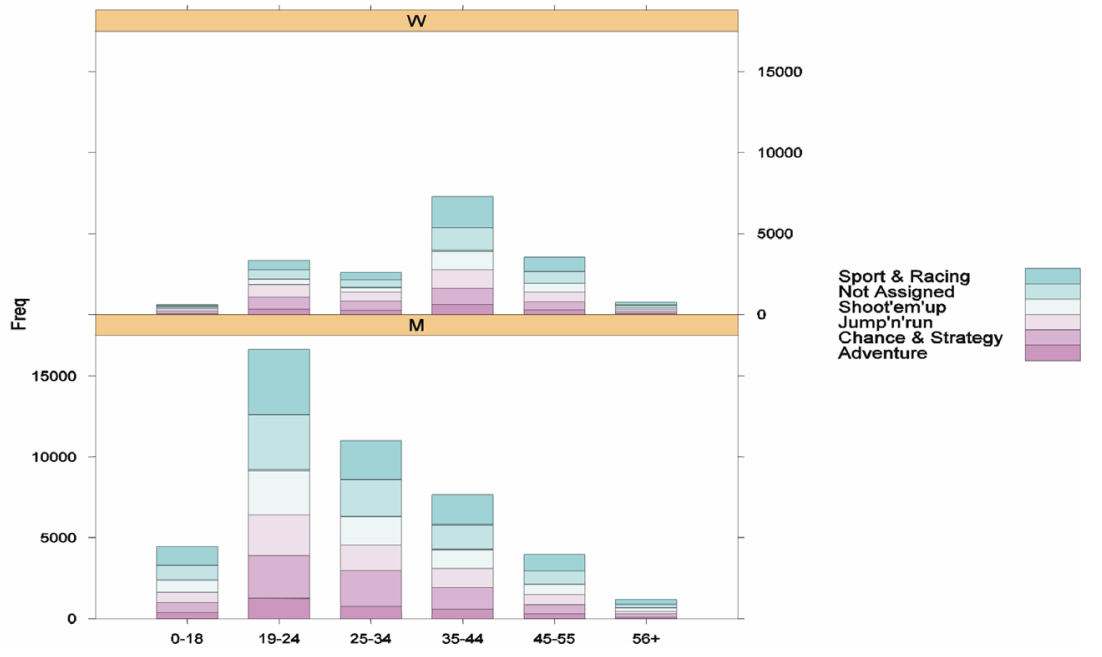

Figure 3: Downloads 2003, grouped by Gender, Age, and Genre $(\mathrm{N}=74.703)$. $\mathrm{W}=$ women, $\mathrm{M}=\mathrm{men}$. 
Later findings regarding the genre distribution (see below) let us suspect that this might be an artifact created by children using the mobile phone of their mothers for game playing. This traceability problem is an indicator for the poor quality of our data, typical for transaction data (cf. [Treib03]). In addition, children typically use prepaid phone cards (see, e.g., [Stan03]), and therefore are underrepresented in the data at hand. However, it is clear that most gamers are young people: even in this probably biased data, almost $60 \%$ are under 35 of age, which is consistent with our findings from the literature (cf. the group of "young adults" in Section 2.5)

In order to get a better impression of the customers' preferences, we now explore the proportion of genres in the downloads, again grouped by age and gender (see Figure 4):

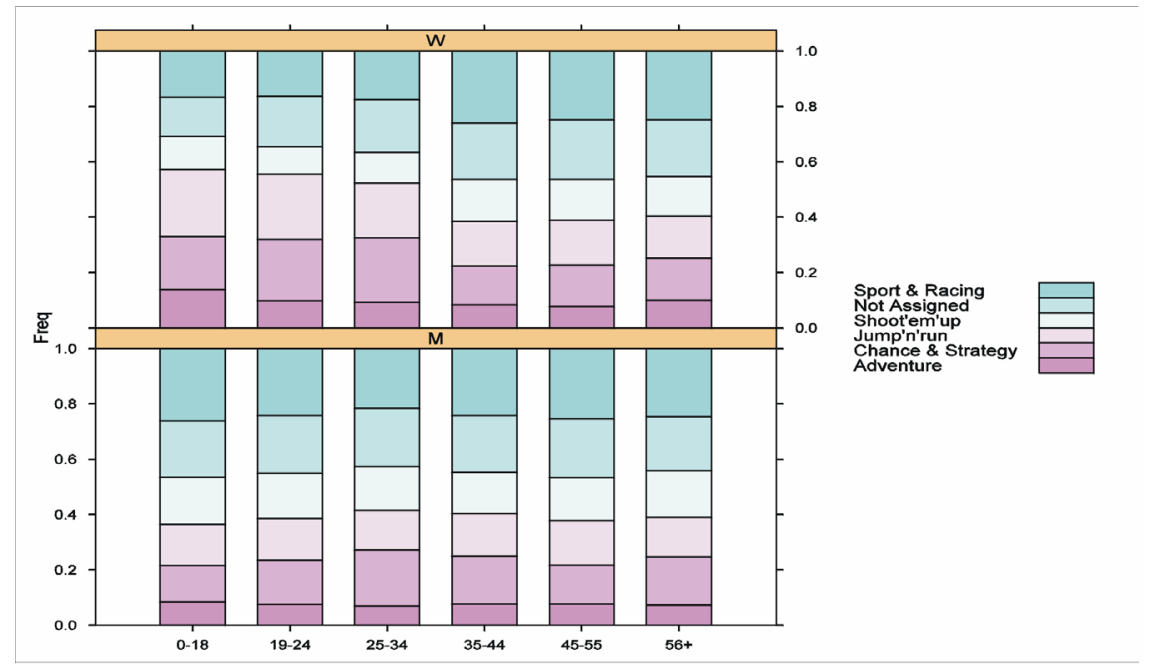

Figure 4: Proportion of Download-Genres, grouped by Age and Gender $(\mathrm{N}=74.703)$

For male customers, the proportion of "Chance \& Strategy" games varies over the age groups, increasing for the first three age groups, and then decreasing. This category removed, the groups seem relatively homogeneous. Therefore, a marketing campaign for "Chance \& Strategy" games should take into account the age of (male) target customers. For female customers, we first note that the bar plot conveys the counter-intuitive impression that middle-aged and elderly women (age groups 4-6) would prefer sport and racing games-it is more likely that much younger and partly male customers (children borrowing the mobile phone from their mother, contracts officially concluded for children, etc.) are the real players here. Therefore, these data have to be interpreted with care. Assuming that the data for younger female customers (age groups 1-3) are reliable, we note that 
here, the proportions of "Sport \& Racing" and "Shoot'em up" games are lower than for male customers, in contrast to the percentages of "Chance \& Strategy" games.

A more substantial finding concerns the influence of branding: although only $22 \%$ of all offered games are branded games, they represent $40 \%$ of all downloads. This positive branding effect is in accordance with the findings from the literature review in the previous section.

\subsection{Customer Segmentation}

Since our primal goal was the segmentation of customers, we conducted a cluster analysis using Self Organizing Maps (see, e.g., [OnAb99] and [Kask95]), a widely used technique for clustering and visualization of multidimensional data. We chose the "Viscovery Profiler" implementation by Eudaptics (see http://www.eudaptics.com). We included all socio-demographic data (age, location, professional background, gender, family status, and rate) for determining the clusters. Note that we did not include the number of downloads, since our aim is to recover homogeneous download characteristics in the clusters. The optimal number of clusters was determined using the cluster index for the SOM-Ward clustering method offered by the software. Three clusters turned out to be the best solution (see Figure 5).

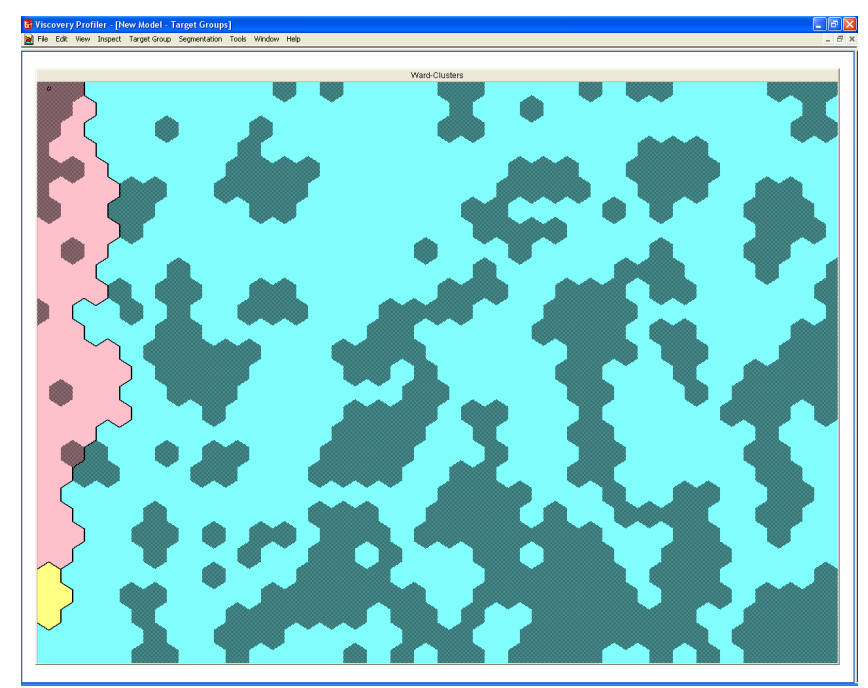

Figure 5: Three-Cluster-Solution using Ward-Clustering.

The grey nodes represent frequent downloaders (more than three games in 2003).

Inspecting the cluster profiles, it appears that two smaller clusters are dominated by married people (and probably could be merged into one cluster). Using the 
"profiling" function of the software, we then in vestigated the importance of the "number of downloads" variable within the cluster solution found in the previous step (shaded areas in Figure 5). Clearly, no cluster exhibits an important "concentration" of downloads, i.e., the socio-demographic variables do not seem to contribute to the explanation of the number of downloads. We therefore believe that other (or at least complementing) variables would be needed to accomplish a successful segmentation.

\subsection{Discussion of Findings}

The results of the data analysis can be summarized as follows:

1. Only few customers are frequent downloaders: Many customers download one or two games, but just a few are regular users.

2. Java-Games players are young people. This is in accordance with our findings from the literature. In our data, we find that at least $60 \%$ of the customers are under 35 (probably more taking into account the "mismatch" of underaged people - see point 5 below).

3. Genre preferences are different for male and female users: Not surprising, male gamers seem to prefer "Shoot'em'up" and "Sport \& Racing" games, whereas female players tend more to the "Jump'and Run" and "Chance \& Strategy" categories. In addition, the preference of male customers for "Fun \& Strategy" games seems to vary over the age groups.

4. Branding has a positive effect on download rates. Again, this result can be recovered in the literature.

5. Transaction data are of limited reliability: Most probably, age and gender bias is present in the data. Underage customers are not well represented, since their bills are officially paid by adult people. A study by the Austrian mobile-phone provider Mobilkom underlines this assumption, showing that $49 \%$ of the 6 to 10 year old and over $90 \%$ of the 11 to 14 year old children have their own mobile phone, and that a major part (82\%) of the bills is paid by parents [Mobi03].

Apart from the apparent necessity of validity checking, the data raise several questions regarding the explanation of the download rates:

1. No profiled download patterns could be recovered from customer segments: We did expect to find clusters associated with high (low) download rates, but given the cluster solution described, there is no evidence in our data that downloads can be explained by socio-demographic variables. We believe that additional data, coming from classical consumer surveys and market data, are needed for recovering useful consumer segmentations. 
H9: Coupling transactional data with survey data on consumer preferences regarding Java Games enables finding a sensible segmentation using clustering methods.

2. Download data do not describe actual use of java games: Java games can be downloaded once but played as often as the customer wishes. The number of downloads can only give us a clue how many games a customer has on his mobile phone, but we do not know how often the users do play, for how long, in which situation. But especially this context of usage is indispensable information to create the right games for the right people [MoRu04].

H10: Consumers do not need a huge variety of games. They regularly play selected games.

H11: The choice of the game is situation-dependent.

3. Download data cannot explain low by-user-downloads. Nothing is known about non-customers: Apart from the users who are satisfied with one or two games, there are probably non-satisfied users as well who discontinue purchasing. This distinction cannot be made from our data. Also, we do not know why potential customers do not purchase java games at all. The motives remain unclear: are the products not fulfilling the consumers' expectations? Are they too expensive? Are the consumers' mobile phones not java-enabled? Are potential customers aware of java games after all? Such questions can only be answered by a consumer survey (phase 4 of our project).

H12: The games available do not meet the consumers' preferences.

H13: The games are currently too expensive.

H14: Java games are unknown to customers. Promotional activities have not been noticed.

\section{Conclusion and Outlook}

Despite of apparent gaps in the specific MJG literature, there is evidence that easeof-use product design, pricing, and branding are the key instruments for the marketing of Java Games. Technological barriers such as limitations of mobile devices and band width possibly have negative impact on customer acceptance. Transaction data typically available to mobile service providers have limited reliability, and furthermore cannot provide answers to the most relevant questions regarding customer behavior. In particular, they do not lead to sensible customer segmentations explaining purchases. 
The following project steps as illustrated in Figure 6 will be the qualitative study with two focus customer groups and one expert group in phase 3 and a customer survey in phase 4 . The focus groups (Phase 3 ) will be selected according to their experience with the internet, mobile phones, MJG, and Computer Console games. The participants will be asked to download games and answer a questionnaire about their experience and factors, which have an impact on their attitude towards downloading MJG. In the next step, the participants will be requested to play games on mobile phones. All participants will receive a unique device and the instruction to operate them. Afterwards they will answer a questionnaire about their experiences using the devices. Interviews with experts will be conducted in parallel. The collected data will be analyzed and used to modify the hypotheses created so far. In the final phase, we will conduct a consumer survey to test the hypotheses derived from the previous phases. As MJG are a relatively young technology, the survey will be constructed on the basis of a standard technology acceptance model such as the UTAUT (Unified Theory of Acceptance and Use of Technology) model [Vank03].

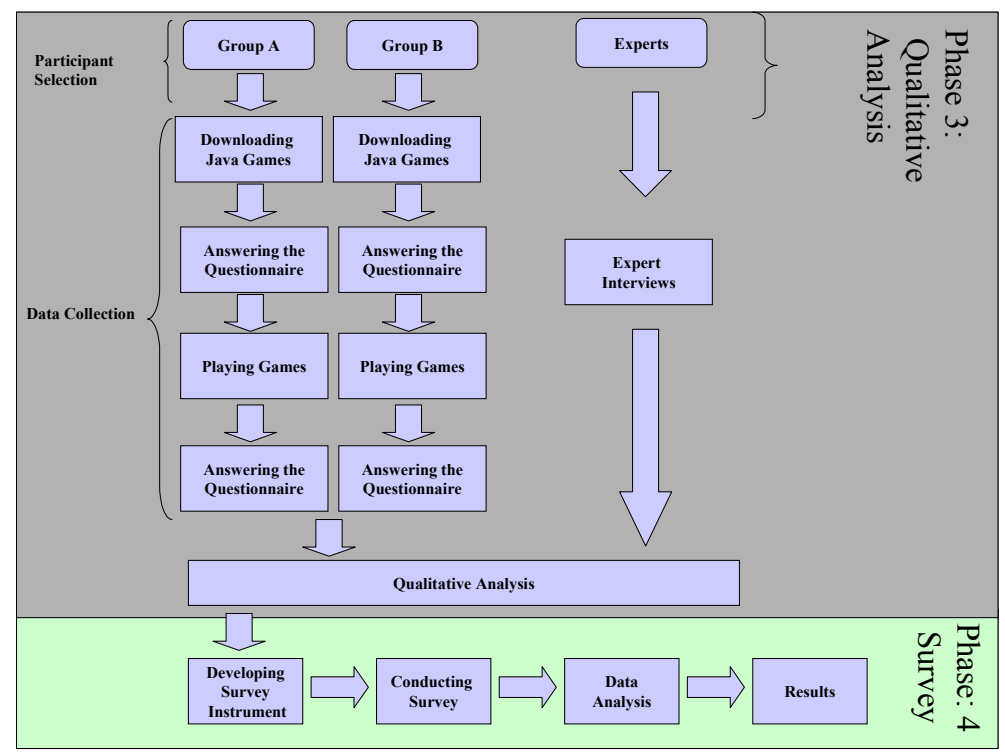

Figure 6: Proposed Design for next project phases 


\section{References}

[Ande02]: Andersen Consulting: 'Mobile Multimedia Study'. European Commission. Directorate-General Information Society, 2002.

[Abou04]: About IT: Jamba! startet als Erster Java-Spiele zum Downloaden für das Handy, http://www.aboutit.de/view.php?ziel=/02/01/04.html (Accessed 2004-06-01).

[Brio01] Briody, D.: The Kids are Alright, Red Herring 2001, http://www.redherring.com/Article.aspx?a=5119\&hed=The+kids+are+alright, (Accessed 2004-07-11).

[Curry ${ }^{+} 03$ ] Curry, B., Davis,F., Evans, M., Moutinho,L., Phillips,P.: The Kohonen selforganising map as an alternative to cluster analysis: An application to direct marketing. International Journal of Market Research. Henley-on-Thames: Second Quarter 2003. Vol. 45; p. $191 \mathrm{ff}$.

[Datc02] Datacomm Research: Winning Business Strategies for Mobile Games, market report, 2002.

[Datm01] Datamonitor: Best Practice in Asia-Pacific Mobile Gaming, Report, , 2001.

[FrSu02] Frost \& Sullivan: Global Mobile Gaming Markets. San Jose 2002.

[Gele04] Gelenbe, P.: Java is.... the new black, http://www.flytxt.com/cgibin/template.pl?t=nrpd\&ID=28, 2004 (Accessed 2004-04-01).

[GrHu00] Granger, V., Huggins, K.: Wireless Internet - More than Voice: The Opportunity and the Issues. Report, Merrill Lynch Global Securities Research \& Economic Group, June 2000.

[Giga02] What Does the Future Hold for Handheld Devices? Giga Information Group, Inc. March 1, 2000.

[Hall01] Hall, J.: Chatty Teens Seen As Growth Market for Wireless, Reuters Technology News, 17 February.Harvard Business School Press, 2001.

[Jamb03]: Public sources, Sun Microsystems, Gartner, ARC Group; Yankee Group; Nokia; Jamba.de.), 2003.

[Kang04] Kangas, S.: International Comparison of Mobile Entertainment, in: Proceedings of Mobile Entertainment: User-centred Perspectives, Manchester 2004.

[Kaski95] Kaski, S., Kohonen, T.: Exploratory Data Analysis by the Self-Organizing Map: Structures of Welfare and Poverty in the World, Proceedings of the Third International Conference on Neural Networks in the Capital Markets, World Scientific, Singapore, 1995, 498-507.

[Kask97] Kaski, S.: Data Exploration Using Self-Organizing Maps. Doctorate Thesis, Neural Networks Research Centre, Helsinki University of Technology, 1997.

[Koho95] Kohonen, T.: Self-Organizing Maps, Springer, 1995.

[Kell03] Keller; K. L.: Strategic Brand Management - Building, Measuring, and Managing Brand Equity, Prentice Hall: Upper Saddle River, 2003. 
[MMAN] Mobile Media Analyse, February 2003

[Mobi03] Mobilkom Austria, "Netzwerkkinder-Studie", http://www.telekompresse.at/channel_electronics/background_10071.html (Accessed 2004-06-11).

[Mobi04] Mobilkom Austria, Download Games: 1 x zahlen - ewig spielen, http://www.a1.net/CDA/article/art_display/0,2564,31-1057-42546-html-de,00.html, (Accessed: 2004-07-11).

[MoRu04] Rutter, J.; Moore, K.: Understanding Consumers' Understanding of Mobile Entertainmentin: Proceedings of Mobile Entertainment: User-centred Perspectives, Manchester 2004.

[Mül199] Müller-Veerse, Falk: Mobile Commerce Report. Durlacher Research Ltd. 1999.

[Noki03] Nokia Corporation. 2003. Introduction to Mobile Java Games, http://nds1.forum.nokia.com/nnds/ForumDownloadServlet?id=2896\&name=Introductio n_to_Mobile_Games_Business_v1_0.pdf(Accessed: 2004-06-11).

[Noki04] White paper Java TMtechnology enables exciting downloading services for mobile users, 2004.

[Obri03] Stuart, O.: Lack of data means mobile games market size remains a mystery. In: Mobile Games Analyst Volume 1, Number 1, 13. November 2003, p. 2.

[OnAb99] Ong, Jason, and Abidi, Syed Sibte Raza: Data Mining Using Self-Organizing Kohonen maps: A Technique for Effective Data Clustering \& Visualisation. In: International Conference on Artificial Intelligence (IC-AI'99), June 28-July 1 1999, Las Vegas, 1999.

[Part01]: Partanen, J.P.: Mobile Gaming: A Framework for Evaluating the Industry 20002005, Gaptime Century, Ltd., 2001.

[Rome03] Q\&A with John Romero of Monkeystone Games, Version 1.0; October 13, 2003.

[Stan03] Der Standard, „Kommunikation per Knopfdruck“ (18.11.2003) http://derstandard.at/?url=/?id=1470694\%26_range=5 (Accessed 2004-10-12).

[Stat04] Statistik Austria, Statistisches Jahrbuch Österreichs 2004.

[Treibl03] Treiblmeyer, H.: Die Bedeutung der Qualität elektronisch gewonnener Daten für die individualisierte Kommunikation, der markt: Zeitschrift für Absatzwirtschaft und Marketing, (166/167), 3+4, 2003, pp. 162-174.

[Ults02] Ultsch, A.: Emergent self-organising feature maps used for prediction and prevention of churn in mobile phone markets, Journal of Targeting, Measurement and Analysis for Marketing; 10,4; June 2002, pp 314-324.

[WAP99] WAP White Paper AU-System Radio AB, AU System Thailand Liberalization, Telecom Journal,February 2002, pp.8-9.

[Wire04] Nokia and Sun to Drive Multiplayer Mobile Java Gaming, Wireless Business Technology, July 2004. http://www.sys-con.com/story/?storyid=45488 (Accessed 2004-10-14) 